\title{
A COVID-19 E O INTERVENCIONISMO JUDICIAL: A DECRETAÇÃO DE LOCKDOWN NA REGIÃO METROPOLITANA DE SÃO LUÍS-MA POR MEIO DE DECISÃO JUDICIAL
}

\author{
Anne Harlle Lima da Silva Moraes ${ }^{1}$ \\ Bernardo Silva de Seixas ${ }^{2}$ \\ Bruno Carvalho Marques dos Santos ${ }^{3}$
}

\section{RESUMO}

Este trabalho tem o escopo de abordar juridicamente a forma como o Estado brasileiro vem enfrentando a pandemia de Covid-19. A delimitação da temática analisará a decisão judicial que determinou a implementação da política pública de isolamento social denominada de lockdown na região metropolitana e em São Luís, capital do Estado do Maranhão. A problemática que orienta o trabalho é se o Poder Judiciário pode determinar políticas públicas de isolamento social durante o período de calamidade pública da Covid-19. O objetivo principal é demonstrar como são resolvidos os conflitos entre os poderes para implementação de políticas públicas durante a pandemia.

PALAVRAS-CHAVE: COVID-19; Políticas Públicas; Direito à Saúde; Poder Judiciário. Lockdown.

\section{COVID-19 AND JUDICIAL INTERVENTIONISM: THE DECISION OF LOCKDOWN IN THE METROPOLITAN REGION OF SÃO LUÍS-MA THROUGH JUDICIAL DECISION}

\begin{abstract}
This work aims to legally address the way the Brazilian State has been facing the Covid-19 pandemic. The delimitation of the theme will analyze the judicial decision that determined the

\footnotetext{
${ }^{1}$ Doutoranda em Direito pela Faculdade Autônoma de Direito de São Paulo (FADISP/ALFA, 2018). Mestre em Desenvolvimento Regional pela Faculdade Alves Faria (ALFA/GO, 2016). Especialista em Direito do Trabalho e Processo do Trabalho pela Universidade Anhanguera (UNIDERP, 2010). Especialista em Advocacia Trabalhista pela Universidade Anhanguera (UNIDERP, 2013). Graduada em Direito pela Faculdade de Imperatriz (FACIMP, 2007). E-mail: anneharlle@ hotmail.com.
}

\footnotetext{
${ }^{2}$ Doutorando em Direito pela Faculdade Autônoma de Direito de São Paulo - FADISP. Mestre em Direito Constitucional pela Instituição Toledo de Ensino de Bauru - ITE/Bauru. Especialista em Processual Constitucional e Garantia de Direitos pela Universidade de Pisa - Itália. Especialista em Direito Processual pelo Centro Universitário de Ensino Superior do Amazonas (CIESA). Professor de Pós-graduação Lato Sensu em Direito da Universidade Federal do Amazonas e do CIESA. Professor de Graduação em Direito da UFAM e CIESA. Advogado licenciado. Assessor de Desembargador no Tribunal de Justiça do Estado do Amazonas. Email: seixas.bernardo@gmail.com.

${ }^{3}$ Doutorando em Direito pela Faculdade Autônoma de Direito de São Paulo (FADISP/ALFA, 2018). Mestre em Desenvolvimento Econômico pela Universidade Candido Mendes (UCAM/RJ, 2016). Especialista em Direito Público pela Fundação Escola de Defensoria Pública do Estado do Rio de Janeiro (FESUDEPERJ/RJ, 2008). Possui MBA em Gestão de Negócios Sustentáveis pela Universidade Federal Fluminense (UFF/RJ, 2012). Graduado em Direito pela Universidade Estácio de Sá (UNESA/RJ, 2006). É Professor da Universidade Gama e Souza, atuando na disciplina de Direito do Administrativo. brunocms@yahoo.com.br.
} 
implementation of the public policy of social isolation called lockdown in the metropolitan region and in São Luís, capital of the State of Maranhão. The problem that guides the work is if the Judiciary can determine public policies of social isolation during the public calamity period of Covid-19. The main objective is to demonstrate how conflicts between the powers to implement public policies are resolved during the pandemic.

KEYWORDS: COVID-19. Public policy. Right to Health. Judiciary; Lockdown.

\section{INTRODUÇÃO}

A pandemia de Covid-19 tem assolado a população mundial, sendo público e notório que todas as regiões do planeta vêm sofrendo com falecimentos de sua população em decorrência da contaminação deste patógeno.

No Brasil a situação de calamidade pública se encontra decretada desde 20 de Março de 2020, por decreto do Presidente da República, contudo, diferentemente dos demais Estados, as políticas públicas de enfrentamento do Covid-19 tem sido objeto de conflito de entre os poderes constituídos e os entes federativos.

Ora, sem olvidar da utilização desta pandemia para fins políticos, desde as implementações de isolamento social é recorrente os conflitos entre os representantes da União Federal e os governadores de Estado sobre quais são as melhores formas de combate ao vírus.

Além disso, a questão da implementação do isolamento social e sobre qual ente estatal tinha a competência para determinar a sua implementação teve que ser decidida pelo Supremo Tribunal Federal ante à complexa divisão de atribuições administrativas no âmbito do direito fundamental à saúde. Ainda, de forma mais específica sobre a atuação do Poder Judiciário houve o deferimento de tutela provisória de urgência para instaurar na região metropolitana e na capital do Estado do Maranhão o denominado Lockdown, tendo o órgão de primeira instância definido a política pública de enfrentamento à pandemia em substituição ao Poder Executivo.

Portanto, este trabalho se justifica pela situação jurídica que a pandemia de Covid-19 instaurou no Brasil, conforme mencionada anteriormente, assim como as inúmeras ações judiciais que provocaram o Poder Judiciário a decidir fatos jurídicos que surgiram ou foram influenciados pela pandemia de Covid-19. 
Assim, os questionamentos que orientam este ensaio são: Qual(is) ente(s) é o competente(s), segundo a Constituição Federal (CF/88), para implementar políticas públicas de saúde ao combate da Covid-19? O Poder Judiciário pode interferir na escolha da política pública implementada pelo Poder Executivo? O Poder Judiciário pode impor uma política pública ao Poder Executivo?

Como objetivo geral este trabalho visa pesquisar sobre as interferências do Poder Judiciário na implementação de políticas públicas de saúde no combate ao Covid-19. Por sua vez, os objetivos específicos são discorrer sobre a pandemia de Covid-19; analisar a repartição de competências administrativas previstas na $\mathrm{CF} / 88$ sobre o direito fundamental à saúde; Examinar a decisão do Supremo Tribunal Federal que fixou a competência de Estados e Municípios para implementação de políticas de isolamento social e, por fim, buscar a razão de decidir da decisão judicial proferida por órgão de primeira do Poder Judiciário do Maranhão que determinou o lockdown.

Para tanto, por meio do método hipotético dedutivo, o primeiro tópico deste ensaio discorrerá sobre a pandemia de covid-19, tratando especificamente da questão brasileira sobre o trato desta tragédia de saúde pública.

Após se discorrerá sobre a Federação brasileira e a repartição de competências administrativas contidas no texto constitucional, em especial a questão atinente ao ente público competente para implementar as políticas de isolamento social.

Por fim, o último tópico abordará a atuação do Poder Judiciário na implementação do lockdown na região metropolitana e na capital do Estado do Maranhão.

\section{A PANDEMIA DE COVID-19}

Acredita-se que a pandemia de Covid-19, causada pelo vírus SARS-CoV-2 ou Novo Coronavírus tenha se manifestado inicialmente em dezembro do ano de 2019, com um surto que afetou aproximadamente 50 pessoas na cidade de Wuhan, na China. Os pacientes afetados, em sua maioria, tinham sido expostos ao mercado Huanan. O mercado em referência comercializava animais silvestres e frutos do mar, estes animais eram vendidos vivos ou abatidos no local. Entretanto, alguns pacientes dessa manifestação inicial não tiveram relação epidemiológica direta com o mercado, gerando a discussão que outras fontes de infecção pudessem estar envolvidas. 
Considerada uma crise mundial com faces múltiplas (social, econômica, sanitária, científica, política, etc.) a Organização Mundial da Saúde (OMS) declarou, em 30 de janeiro de 2020, que o surto da doença causada pelo novo coronavírus (COVID-19) constitui uma Emergência de Saúde Pública de Importância Internacional - o mais alto nível de alerta da Organização, conforme previsto no Regulamento Sanitário Internacional. Em 11 de março de 2020, a COVID-19 foi caracterizada pela OMS como uma pandemia, por ser uma enfermidade amplamente disseminada. Foram confirmados no mundo 3.759.967, segundo a OMS, casos de COVID-19 (87.729 novos em relação ao dia anterior) e 259.474 mortes (5.429 novas em relação ao dia anterior) até 8 de maio de 2020.

Ocasionou mais de 280 mil mortes no mundo, conforme os dados da Organização Mundial da Saúde e 11.427 óbitos no Brasil, segundo os dados fornecidos pelo Ministério da Saúde datados de 10 de maio de 2020.

Estima-se que o número de infectados e mortos concorrem diretamente com o impacto sobre os sistemas de saúde público e privado, com a exposição da população e especificamente alguns grupos vulneráveis.

Com sintomas gerais de gripe, essa patologia é mais agressiva em pessoas consideradas integrantes do grupo de risco, idosos, portadores de doenças crônicas, diabéticos, hipertensos, isso se dá em virtude do vírus atacar principalmente o sistema respiratório dessas pessoas mais fragilizadas.

Assim, em virtude dessas complicações mais graves, o número de pessoas que necessitam de atendimento hospitalar é muito alto e com isso os sistemas de saúde ficam superlotados, tanto hospitais públicos, quanto privados, não possuem estrutura suficiente para atender toda a população que carece de atendimento, até mesmo por não haver profissionais de saúde na quantidade que supra a demanda de infectados, assim como também não há respiradores mecânicos e leitos suficientes para o combate ao vírus.

A seriedade da doença que até então não tem cura, em conjunto com a ausência de estruturas hospitalares, poucos profissionais e esgotamento dos equipamentos necessários ao combate ao vírus, acarretou ao mundo adotar o isolamento social como uma medida de prevenção, onde em decorrência do avanço da epidemia, não é possível atender todos que necessitam do sistema, logo, o isolamento social visa retardar a transmissão do vírus.

Com isso, os entes federativos adotam medidas políticas no combate a essa patologia, mas há demasiada divergência sobre quais os meios eficazes a serem utilizados. As 
medidas instituídas objetivando a contenção da propagação do coronavírus impactam, diretamente na economia do país e especificamente nas empresas.

Sobre a natureza jurídica do distanciamento social, Carlos Eduardo Behrmann Rátis Martins (2020, p.55) defende que este seja considerado como um dever fundamental

\begin{abstract}
É o caso do dever geral de recolhimento domiciliar em tempos de coronavírus, que para ser admitido como novo dever fundamental, precisa apresentar densidade jurídica suficiente, até porque os deveres fundamentais não são meras imposições assentadas em virtudes humanas. Constituem, em verdade, num modelo recíproco próprio do contrato social, onde por fim, os cidadãos terão dever de obediência ao Estado. O Estado por sua vez terá o dever de garantia de direitos e assim se desenvolverá a sociedade política. O dever geral de recolhimento domiciliar se traduz em sujeições à limitação de circulação em espaços e vias públicas, ou em espaços e vias privadas equiparadas a vias públicas, buscando conter os efeitos do crescimento desenfreado do número de casos de COVID-19 e inevitável sobrecarga de atendimentos nas unidades hospitalares. Essas imposições só poderão ser consideradas compatíveis com a Constituição se forem essenciais, adequadas e proporcionais, objetivando restringir o direito de locomoção para proteger o bem maior que é a saúde pública e a vida de todos brasileiros. As medidas de isolamento social sempre deverão ser justificadas, em termos de necessidade e razoabilidade.
\end{abstract}

É um fato que o isolamento social é imprescindível no momento, porém, a divergência entre o discurso do Presidente da República que defende o isolamento social vertical através da promulgação da Lei $\mathrm{n}^{\circ}$ 13.979/2020 (Dispõe sobre as medidas para enfrentamento da emergência de saúde pública de importância internacional decorrente do coronavírus responsável pelo surto de 2019.), determinou que deve-se isolar somente as pessoas infectadas ou suspeitas de contaminação pelo vírus entra em divergência com o que determina os Governadores de alguns estados da federação.

É cediço que esse conflito federativo leva a uma insegurança jurídica em um momento que a população mais necessita de informações seguras, contudo, apesar da mencionada lei determinar o isolamento parcial, a maioria dos Estados adotou o isolamento de toda a população e não somente de uma parcela, conforme disposto na lei federal.

Dessa forma, o tópico seguinte analisará esse conflito de competência para legislar sobre as políticas públicas a serem adotadas, levando em conta o pacto federativo e autonomia dos entes.

\title{
3 O CONFLITO FEDERATIVO PARA IMPLEMENTAÇÃO DAS POLÍTICAS PÚBLICAS DE COMBATE À PANDEMIA
}


A CF/88 define que o Estado brasileiro se constitui como uma Federação, estipulando, ainda, que a forma de estado é uma cláusula pétrea onde o poder constituinte reformador não poderá propor proposta de emenda à Constituição tendente a abolir o estado federal brasileiro. José Adércio Leite Sampaio (2013, p. 298) comenta que

A Constituição brasileira impede que uma série de matérias, princípios e regras constitucionais sejam alteradas. Não pode ser objeto de deliberação proposta tendente a abolir a forma federativa de Estado; o voto direto, secreto, universal e periódico; a separação dos poderes e os direitos e garantias individuais [...].

A finalidade desta forma de Estado é constituir um ente central forte que irá exercer competências próprias e em paralelo com os demais entes, contudo sendo detentor de soberania. Diversamente, os estados-membros que formam a federação são detentores de autonomia, seja ela administrativa, legislativa ou financeira. Sobre essa forma de estado, é a lição de Barroso (2016, p. 206-207)

Federação significa a forma de Estado, o modo como se dá a distribuição espacial do poder político. Nesse tipo de organização, em lugar de existir um único centro de poder, existem dois: o central e o federado. A forma federativa de Estado procura conciliar o respeito à diversidade de cada entidade política com elementos de unidade indispensáveis à preservação da soberania e da integridade nacionais.

A federação se caracteriza pela proibição de secessão, a criação de entes federativos e, principalmente, a questão referente à repartição de competências dos diversos entes que compõem a federação. Ainda, às características anteriormente citadas por Barroso (2016, p. 207) indica que "De forma sumária, a caracterização do Estado Federal envolve a presença de três elementos: a) repartição de competências [...], b) autonomia [...] e c) participação na formação da vontade do ente global [...]".

A proibição de secessão é uma tentativa de manutenção do pacto federativo, onde se impossibilita que qualquer ente que se uniu para formação da federação se segregue, fragilizando o próprio Estado. No Brasil, há mecanismos criados aos entes para impedir qualquer afronta ao pacto federativo, se instrumentalizando, em especial, com a intervenção federal, contida no art. 34, CF/88.

Sobre a vedação à secessão são os comentários de Fernanda Dias Menezes de Almeida (CANOTILHO et al, 2015, p. 110) 
Não há na federação o direito de secessão, em virtude [...] dos estados-membros não serem detentores de soberania que enseja o rompimento dos vínculos federativos. Bem por isso é que não contraria a lógica do sistema a previsão de cláusula constitucional proibindo expressamente o desligamento dos entes federados ou, ao menos, de cláusula de que decorra implicitamente esta proibição, como a que estabeleça serem indissolúveis os laços federativos. Pela mesma razão é que igualmente tem sentido a existência de um mecanismo de defesa como a intervenção federal, acionável basicamente quando em risco a unidade nacional.

Ainda, a federação brasileira se particulariza com a inclusão de mais entes federativos do que os demais Estados que elegem a federação como forma de Estado. Ora, o ordinário das federações ocidentais é a divisão e distribuição de poder em apenas dois níveis, ou seja, o ente central e o estado-membro.

No entanto, no Brasil, por uma escolha soberana do poder constituinte originário, os municípios foram alçados ao status de ente federativo, conforme se verificar no art. $1^{\circ}, \mathrm{CF} / 88$. Assim, no atual estágio constitucional, se entende como entes federativos, tanto a União Federal, como os Estados-Membros, o Distrito Federal e os Municípios.

Por fim, quanto às características da federação, resta a repartição de competências previstas entre os arts. 21 a $24, \mathrm{CF} / 88$.

O texto constitucional cria, inicialmente, duas espécies de atribuições uma de maneira administrativa outra de função normativa, ainda, não se olvida das competências tributárias previstas nos arts. 153 a 156, CF/88, todavia, em razão dos limites deste trabalho essas não serão abordadas.

A competência legislativa encontra-se prevista no art. 22 e 24, CF, sendo que no primeiro há a indicação expressa das competências privativas da União para legislar sobre as matérias elencadas de forma taxativa pelo texto constitucional. No art. 24, CF/88 constata-se as competências legislativas concorrentes onde se verifica a possibilidade de coexistência entre legislação federais e estaduais de determinada matéria, já que compete à União legislar em âmbito geral e ao ente estadual suplementar a legislação federal para atender as suas particularidades.

$\mathrm{O}$ art. 21, CF/88 estabelece as competências administrativas ou materiais da União Federal, estabelecendo o que compete à entidade federal realizar através de atos administrativos. Aqui cabe uma ressalva imprescindível ante a impossibilidade de delegação dessas atribuições para os demais entes da federação, ou seja, somente a União Federal poderá atuar nas matérias expressamente contidas nos incisos do dispositivo da Constituição, sendo que esta competência é denominada de exclusiva. 
Por sua vez, o art. 23, CF/88 estabelece as competências administrativas comuns, ou seja, aquelas em que todos os entes da federação poderão atuar. Neste dispositivo normativo se constata a atuação em conjunto de todos os entes federativos para alcançar o máximo de efetividade no cumprimento das determinações constitucionais em âmbito, por exemplo, de saúde.

Em decorrência do corte metodológico deste ensaio, o que se aborda de forma específica é a questão referente ao direito à saúde e a competência administrativa comum dos entes federativos para atuarem na implementação desta política pública.

Ora, nos termos do art. $6^{\circ}, \mathrm{CF} / 88$, o direito à saúde se configura como um direito fundamental de segunda dimensão, em que se necessita de uma atuação do Estado para implementação e efetivação deste direito. Importante é a lição de Sarlet (2012, p. 47)

A nota distintiva destes direitos é a sua dimensão positiva, uma vez que se cuida não
mais de evitar a intervenção do Estado na esfera da liberdade individual, mas, sim,
[...] propiciar um "direito de participar do bem-estar social. Não se cuida mais,
portanto, de liberdade do e perante o Estado, e sim de liberdade por intermédio do
Estado. [...] caracterizam-se, ainda hoje, por outorgam ao indivíduo direitos a
prestações sociais estatais, como a assistência social, saúde [...].

Ainda, a saúde é prevista no art. 196, onde se estipula como uma obrigação solidária, segundo a jurisprudência do STF, entre todos os entes federativos a implementação das políticas públicas referente à saúde à população brasileira.

O entendimento do STF foi reconhecido, com repercussão geral, no Recurso Extraordinário (RE) n. 855.178/RG (BRASIL, 2020) nesses termos:

CONSTITUCIONAL E ADMINISTRATIVO. EMBARGOS DE DECLARAÇÃO EM RECURSO EXTRAORDINÁRIO COM REPERCUSSÃO GERAL RECONHECIDA. AUSÊNCIA DE OMISSÃO, CONTRADIÇÃO OU OBSCURIDADE. DESENVOLVIMENTO DO PROCEDENTE. POSSIBILIDADE. RESPONSABILIDADE SOLIDÁRIA NAS DEMANDAS PRESTACIONAIS NA ÁREA DA SAÚDE. DESPROVIMENTO DOS EMBARGOS DE DECLARAÇÃO. 1. É da jurisprudência do Supremo Tribunal Federal que o tratamento médico adequado aos necessitados se insere no rol dos deveres do Estado, porquanto responsabilidade solidária dos entes federados. O polo passivo pode ser composto por qualquer um deles, isoladamente, ou conjuntamente. 2. A fim de otimizar a compensação entre os entes federados, compete à autoridade judicial, diante dos critérios constitucionais de descentralização e hierarquização, direcionar, caso a caso, o cumprimento conforme as regras de repartição de competências e determinar o ressarcimento a quem suportou o ônus financeiro. 3. As ações que demandem fornecimento de medicamentos sem registro na ANVISA deverão necessariamente ser propostas em face da União. Precedente específico: RE 657.718, Rel. Min. Alexandre de Moraes. 4. Embargos de declaração desprovidos. 
Assim, o art. 23, II, CF/88 estabelece a competência comum de todos os entes federativos na concretização das políticas públicas de saúde. E foi neste cenário que surgiu um conflito entre os entes federativos a respeito da implementação das políticas públicas de saúde de combate ao novo coronavírus.

Ora, é notório a atuação dos chefes do Poder Executivo estadual na implementação do isolamento horizontal, onde se implementam políticas públicas de distanciamento social para achatar a curva de contágio da população e evitar o colapso do sistema público de saúde.

No entanto, também é notório a opinião do atual Presidente da República na adoção do isolamento vertical, onde somente parcela da população se enquadra no isolamento social, em especial a população que se encontra em situação de risco, no caso da Covid-19 os idosos, diabéticos, asmáticos e, dentre outros, os hipertensos.

Esta situação se configura como um conflito federativo. Conforme mencionado, a Constituição Federal disciplina uma complexa repartição de competências entre os entes federativos, sendo inerente ao estudo da federação a questão referente ao conflito entre os diversos níveis de poder sobre a quem compete exercer determinada atribuição.

Tanto é frequente o conflito federativo que a Constituição Federal estabelece ao STF a competência para dirimir o litígio entre cada esfera de poder, nos termos do art. 102, "f", CF/88. Sobre essa função é a lição de André Ramos Tavares (2005, p. 297)

\footnotetext{
Considera-se exercício de função arbitral apenas nas hipóteses de se reportar o Tribunal Constitucional à atuação normativa ou material dos poderes, procurando solver os eventuais conflitos que surjam, fundamentada exclusivamente na preocupação de superar o atrito entre entidades constitucionais. [...] verificar-se, portanto, que, apesar da referência inicial restrita ao federalismo, o autor propõe uma função [...] de mediação para todo o conflito derivado na repartição de "poderes" entre autoridades ou órgão [...].
}

Neste cenário que causou conflito federativo entre a União Federal e alguns governadores de Estado-membro o STF foi provocado a se manifestar a respeito de quem compete determinar as medidas de combate à pandemia que assola o território brasileiro.

Tal provocação decorreu do ajuizamento da ação direta de inconstitucionalidade $n$. 6.341 (BRASIL, 2020), ajuizada pelo Partido Democrático Trabalhista, que impugna artigos da Medida Provisória (MP) 926/2020 (BRASIL, 2020).

A MP 926/2020 alterou a Lei $n^{\circ}$ 13.979, de 6 de fevereiro de 2020, para dispor sobre procedimentos para aquisição de bens, serviços e insumos destinados ao enfrentamento da emergência de saúde pública de importância internacional decorrente do coronavírus. Pela 
delimitação temática do tema, o que importa é a disposição contida no art. $3^{\circ}$ e em seus parágrafos, nesses termos:

\begin{abstract}
Art. $3^{\circ}$ Para enfrentamento da emergência de saúde pública de importância internacional decorrente do coronavírus, as autoridades poderão adotar, no âmbito de suas competências, dentre outras, as seguintes medidas: I - isolamento; II quarentena [...] VI - restrição excepcional e temporária, conforme recomendação técnica e fundamentada da Agência Nacional de Vigilância Sanitária, por rodovias, portos ou aeroportos de: a) entrada e saída do País; b) locomoção interestadual e intermunicipal; $[\ldots] \S 8^{\circ}$ As medidas previstas neste artigo, quando adotadas, deverão resguardar o exercício e o funcionamento de serviços públicos e atividades essenciais. § $9^{\circ} \mathrm{O}$ Presidente da República disporá, mediante decreto, sobre os serviços públicos e atividades essenciais a que se referem o $\S 8^{\circ}$.
\end{abstract}

A principal questão suscitada foi se competia somente ao Presidente da República determinar políticas públicas de combate ao coronavírus ou se esta competência também se encontra sob a égide dos governadores e prefeitos.

A questão constitucional é de simples resolução, pois considerando a competência administrativa concorrente dos entes federativos sobre a questão da saúde, constata-se a viabilidade de governadores e prefeitos que atuaram em concomitância com a União Federal na implementação das políticas públicas de saúde, onde cada um deve atuar observando os limites de sua competência, ou seja, a União Federal atuando em âmbito nacional, os Governadores nos limites territoriais de cada estado-membro com a observância dos interesses em âmbito estadual e, por fim, os municípios nos limites territoriais de sua competência, se orientando pelo interesse de âmbito municipal.

A questão é de tão fácil resolução que o Ministro Marco Aurélio Mello, relator da ADI 6.341/DF (BRASIL, 2020), reforça o mero caráter pedagógico da matéria, nesses termos:

\begin{abstract}
Vê-se que a medida provisória, ante quadro revelador de urgência e necessidade de disciplina, foi editada com a finalidade de mitigar-se a crise internacional que chegou ao Brasil, [...]. Há de ter-se a visão voltada ao coletivo, ou seja, à saúde pública, mostrando-se interessados todos os cidadãos. $\mathrm{O}$ artigo $3^{\circ}$, cabeça, remete às atribuições, das autoridades, quanto às medidas a serem implementadas. Não se pode ver transgressão a preceito da Constituição Federal. As providências não afastam atos a serem praticados por Estado, o Distrito Federal e Município considerada a competência concorrente na forma do artigo 23, inciso II, da Lei Maior. Também não vinga o articulado quanto à reserva de lei complementar. [...]Presentes urgência e necessidade de ter-se disciplina geral de abrangência nacional, há de concluir-se que, a tempo e modo, atuou o Presidente da República Jair Bolsonaro - ao editar a Medida Provisória. O que nela se contém - repita-se à exaustão - não afasta a competência concorrente, em termos de saúde, dos Estados e Municípios. Surge acolhível o que pretendido, sob o ângulo acautelador, no item a.2 da peça inicial, assentando-se, no campo, há de ser reconhecido, simplesmente
\end{abstract}


formal, que a disciplina decorrente da Medida Provisória $n^{\circ}$ 926/2020, no que imprimiu nova redação ao artigo $3^{\circ}$ da Lei federal $n^{\circ} 9.868 / 1999$, não afasta a tomada de providências normativas e administrativas pelos Estados, Distrito Federal e Municípios. 3. Defiro, em parte, a medida acauteladora, para tornar explícita, no campo pedagógico e na dicção do Supremo, a competência concorrente.

Portanto, considerando as atuais regras constitucionais quanto à federação brasileira, assim como as regras de repartição de competências, todas as esferas de poder do Estado brasileiro podem atuar e implementar políticas públicas de combate ao coronavírus, mesmo que o representante do ente central não concorde com as medidas tomadas pelos governadores e prefeitos no âmbito de suas competências, eis que entidades dotadas de autonomia e competência administrativa comum para implementação da política de saúde.

Ultrapassada o exame das regras constitucionais sobre a competência na atuação e implementação da política pública de saúde, examina-se a atuação do Poder Judiciário neste contexto de pandemia.

\section{A ATUAÇÃo DO PODER JUDICIÁRIO FRENTE AO COMBATE AO CORONAVÍRUS E A DECISÃO JUDICIAL QUE DETERMINOU O LOCKDOWN NA REGIÃO METROPOLITANA DE SÃO LUÍS-MA}

É cediço que a Constituição Federal estabelece uma rígida separação de poderes, com a diversificação de funções e criação de órgão específicos para exercício de cada competência. Ainda, disciplina o exercício de funções atípicas e as interferências constitucionais legítimas de cada ente em outro.

Ao Judiciário compete, com primazia, a resolução dos conflitos de interesse por intermédio da utilização da sua função típica que é a jurisdição. No entanto, tem se observado uma modificação substancial de atuação dos órgãos do Poder Judiciário desde a promulgação da Constituição Federal de 1988. Sobre essa transformação do Poder Judiciário leciona Leonardo Sarmento (2016, p. 50-51)

Com o passar dos anos, as decisões proferidas pelos Tribunais Superiores passaram a desempenhar um papel central na vida jurídica do país por duas razões primordiais. Em primeiro, a abertura do sistema jurídico acaba por transferir ao magistrado um poder decisório bastante amplo, de modo que é ele quem definirá, afinal, qual o direito vigente sobre determinada matéria, paulatinamente deixando o papel quase que automático de "boca de lei". Ademais, além da evidente persuasão pragmática e lógica associada às decisões de tais cortes, opções legislativas específicas, sobretudo no âmbito do processo civil, têm procurado prestigiar a jurisprudência dos tribunais superiores. 
Ora, como não pode deixar de ser, o Poder Judiciário ainda exerce a competência de resolução dos conflitos de interesse intersubjetivo, o denominado litígio, contudo esta função tem atuado como um verdadeiro órgão transformador das políticas públicas e efetivação dos direitos fundamentais, proferindo, por intermédio das decisões judiciais, inúmeras normas gerais e abstratas para questões que são inerentes à sua competência.

Sobre essa nova atuação do Poder Judiciário menciona-se a posição de Rennan Thamay e José Tesheiner Maria Rosa (2019, p. 55)

\begin{abstract}
$\mathrm{Na}$ atualidade, é certo que o Poder Judiciário edita não apenas normas concretas, mas, também, normas gerais e abstratas, exercendo, pois, também atividade normativa. Essa afirmação é feita com base no Direito brasileiro, mas o fenômeno não se limita ao Brasil. A importância dessa constatação é reduzida nos países do Common Law, que sempre conviveram com as judge made laws, por força da eficácia vinculativa dos precedentes, ainda que se trate de fenômenos distintos.
\end{abstract}

Ainda, a questão da modificação da própria atuação do Poder Judiciário tem se defendido a modificação da própria concepção da decisão judicial, deixando de ser este um instrumento de silogismo e se tornando uma fonte normativa de efetivação do direito por meio da interpretação constitucional. Nesse sentido é a posição de Abboud, Carnio e Oliveira (2015, p. 375-376)

\begin{abstract}
Do mesmo modo que um paradigma só pode ser considerado pós-positivista se trabalhar com novo conceito de norma, da mesma forma, somente será possível instrumentalizar esse novo conceito de norma a partir de um conceito pós-positivista de sentença (decisão judicial). Perante o paradigma pós-positivista, a sentença deixa de ser ato silogístico em que se aplica mecanicamente uma premissa maior (lei) para a solução do caso (premissa menor). [...] a sentença na qual é produzida a norma para solucionar o caso concreto (real ou fictício) ocorre de maneira estruturante, afinal, não existe um descobrir a norma, o que de fato existe é um produzir/atribuir sentido à norma diante da problematização de um caso concreto. [...] Portanto, a decisão judicial perante o paradigma pós-positivista [...] é o modelo fundamental na qual se fundem a compreensão da norma e sua relevância aplicativa.
\end{abstract}

Assim, esta atuação tem gerado argumentos favoráveis e contrários à forma mais proativa do Poder Judiciário na concretização das políticas públicas e na efetivação de direitos fundamentais. Além disso, de forma específica na questão fática objeto deste ensaio, o STF exerce a função de pacificador do conflito de competência, onde é possível, desde que fundamentada, que existam decisões judiciais com caráter político, ou seja, a possibilidade do 
Poder Judiciário resolver conflito oriundo da atuação dos entes federativos no exercício de suas competências.

Alguns argumentos que permitem essa atuação são fundados, principalmente, no amplo acesso ao Poder Judiciário, contido no art. $5^{\circ}, \mathrm{XXXV}, \mathrm{CF} / 88$, bem como a atuação das funções essenciais à justiça na efetivação dos direitos da população vulnerável, assim como a vasta previsão de direitos fundamentais à pessoa humana. Ainda, reforça o argumento de uma atuação proativa dos órgãos do Poder Judiciário a questão das normas constitucionais serem veiculados como cláusulas abertas, onde se permite uma atuação maior do intérprete para interpretar e aplicar o texto constitucional.

Certo é que adicionado aos fatores que permitem o aumento de atuação do Poder Judiciário a questão da pandemia será amplamente discutida perante este órgão estatal, vez que diversas relações jurídicas foram afetadas com a declaração de calamidade pública e com as medidas de isolamento social implementadas pelos governadores e municípios, desde questões locatícias à prestação de serviços educacionais.

Não foi diferente com a questão das políticas públicas impostas pelo Poder Executivo para o combate ao coronavírus. Ora, conforme mencionado existem diversas formas de combater a patologia, sendo a principal a questão do isolamento social e a imposição de quarentena para as localidades mais acometidas com a pandemia.

Todavia, por diversas razões que não são objeto deste estudo, em determinada localidade as medidas de contingenciamento social não foram suficientes, ou seja, a implementação quarentena não foi suficiente para o achatamento da curva de contágio, tendo, em alguns municípios, como em Manaus, capital do estado do Amazonas, a rede pública de saúde entrado em colapso ante ao alto quantitativo de pessoas infectadas.

Assim, para combater a ineficácia da quarentena, tem se defendido uma nova metodologia de distanciamento social, que é denominado de lockdown, que se configura como uma medida mais restritiva de isolamento da população com a impossibilidade de locomoção total da população e o fechamento da atividade comercial, salvo aquele indicada como essencial à manutenção mínima da população.

No entanto, a questão da implementação do lockdown, se é a medida adequada ou não, não é objeto deste trabalho, mas sim a forma como, inicialmente, tem se implementado no território brasileiro, pois, conforme já estudado, a implementação de política pública compete ao Poder Executivo e não, em regra, ao Poder Judiciário. 
A decretação do lockdown na capital do Estado do Maranhão e em sua região metropolitana decorreu de uma ação civil pública ajuizada pelo Ministério Público onde se realizou pedido de tutela provisória de urgência para deferir por um período de tempo determinado a restrição máxima à circulação da população maranhense.

Não se questiona neste ensaio a atuação dos membros do Ministério Público, vez que somente cumprem com suas funções constitucionais em ajuizar as ações coletivas para defesa dos interesses difusos da coletividade, no entanto, se questiona a implementação de um sistema de distanciamento social extremamente rígido mediante decisão judicial precária e fundada em cognição sumária.

Ora, é cediço que o sistema processual permite a imposição de obrigações de fazer aos jurisdicionados que se encontram na relação jurídica processual, com permissão, ainda, de utilização de meios coercitivos para implementação da medida judicial, todavia, se entende com ressalvas o deferimento do lockdown por medida judicial.

Primeiro, em razão da própria característica das tutelas provisórias que são regidas pela cláusula rebus sic actus, ou seja, modificam-se a partir do momento em que os fatos que ensejaram a decisão judicial sofrem modificações.

Ora, é público e notório o fato da desorganização estatal quanto aos números de infectados, assim como as localidades em que se tem uma maior concentração de infectados, logo, permitir que uma decisão judicial tenha o objetivo de impor o denominado lockdown é tornar a medida ineficaz, pois, toda vez que houver uma alteração fática a decisão judicial deverá mudar.

Ainda, o órgão competente para implementação das políticas públicas de saúde é dos chefes do executivo, bem como daqueles que tem o conhecimento adequado para combate às pandemias, principalmente médicos e cientistas, e não um órgão jurisdicional que somente é conhecedor do conhecimento jurídico.

Assim, este trabalho se posiciona pela impossibilidade do Poder Judiciário interferir na questão das políticas públicas de distanciamento social para combate à pandemia do COVID19, ante a interferência indevida na função típica do Poder Executivo.

Ainda, caso provocado, propõe este ensaio que os órgãos do Poder Judiciário se proponham a realizar medidas de autocontenção judicial, ou seja, atuar com observância da cláusula de separação de poderes e indeferir medidas que tão somente competem aos órgãos técnicos do Poder Executivo. 


\section{CONSIDERAÇÕES FINAIS}

Este trabalho se propôs a analisar a atuação do Poder Judiciário no âmbito das políticas públicas de combate à pandemia de coronavírus ante às inúmeras consequências que esta patologia tem causado nas relações humanas.

Os questionamentos que motivaram este trabalho foram: Qual(is) ente(s) é o competente(s), segundo a Constituição Federal (CF/88), para implementar políticas públicas de saúde ao combate da Covid-19? O Poder Judiciário pode interferir na escolha da política pública implementada pelo Poder Executivo? O Poder Judiciário pode impor uma política pública ao Poder Executivo?

Neste sentido, no primeiro tópico, se abordou alguns dados estatísticos da pandemia e como o Estado brasileiro tem se posicionado para diminuir a curva de contágio, proteger a população brasileira e efetivar o direito à saúde àqueles que tem contraído o patógeno.

Após, no segundo tópico, percorreu-se as disposições constitucionais expressas sobre a federação e principalmente a repartição de competências, onde, mediante decisão judicial do STF buscou-se aclarar a dúvida e responder um dos questionamento deste trabalho a respeito de quem competia a implementação da política pública de combate ao coronavírus, tendo a corte constitucional brasileira se posicionado sobre a competência concorrente dos entes da federação para implementação das políticas de combate ao coronavírus, não havendo exclusão da competência dos governadores e prefeitos para implementarem políticas de isolamento social no âmbito de seus territórios.

Por fim, no terceiro tópico, se abordou a decisão judicial proferida pelo órgão do Poder Judiciário do Estado do Maranhão que deferiu a medida de distanciamento social denominada lockdown via decisão judicial.

Buscou-se neste último tópico debater sobre a interferência do Poder Judiciário na implementação de políticas públicas referente à saúde, fato que, no Estado brasileiro, tem se demonstrado normal, ante à precarização do sistema de saúde e ausência de políticas públicas de efetivação do direito à saúde, considerando o caráter ativista assumido pelos órgãos judiciais. 
Todavia, em que pese a situação excepcional que a pandemia de coronavírus tem tomado, mesmo assim, se propõe uma atuação fundada em autocontenção dos órgãos do Poder Judiciário brasileiro.

Neste cenário, não se critica, nem os membros do Ministério Público e nem juízes que deferem medidas para combater de maneira mais eficaz a questão da pandemia, no entanto, mediante uma situação excepcional, mais adequado constitucionalmente, ante à separação dos poderes, é que o Poder Executivo seja o competente para tomar medidas tão drásticas como o lockdown, vez que este e somente este tem a estrutura, técnicos e informações necessárias para impor um política pública tão relevante para a defesa da incolumidade pública.

\section{REFERÊNCIAS FINAIS}

ABBOUD, Georges; CARNIO, Henrique Garbellini; OLIVEIRA, Rafael Tomaz de. Introdução à Teoria e à Filosofia do Direito. 3 ed. São Paulo : Revista dos Tribunais, 2015.

BARROSO, Luís Roberto. Curso de Direito Constitucional Contemporâneo : Os conceitos Fundamentais e a Construção do Novo Modelo. 5 ed. São Paulo : Saraiva, 2016.

BRASIL. Constituição da República Federativa do Brasil de 1988. Disponível em : http://www.planalto.gov.br/ccivil_03/constituicao/constituicaocompilado.htm. Acesso em : 09 MAI 2020.

BRASIL. Ministério da Saúde. Coronavírus: 155.939 casos confirmados e 10.627 mortes. Disponível em: https://www.saude.gov.br/noticias/agencia-saude/46859-coronavirus-155939-casos-confirmados-e-10-627-mortes. Acesso em: 10 MAI 2020.

BRASIL. Supremo Tribunal Federal. Recurso Extraordinário n. 855.178. Relator: Luiz Fux Disponível em https://http://stf.jus.br/portal/jurisprudencia/visualizarEmenta.asp?s 1=000284479\&base=base Acordaos. Acesso em 10 MAI 2020.

BRASIL. Supremo Tribunal Federal. Ação Direta de Inconstitucionalidade n. 6.341. Relator: Ministro Marco Aurélio Mello. Disponível em : https://portal.stf.jus.br/processos/detalhe.asp?incidente=5880765. Acesso em 10 MAI 2020.

BRASIL. Poder Executivo. Medida Provisória n. 926 de 20 de Março de 2020. Disponível em : http://www.planalto.gov.br/ccivil_03/_ato2019-2022/2020/Mpv/mpv926.htm. Acesso em 09 MAI 2020.

CANOTILHO, Joaquim José Gomes; MENDES, Gilmar Ferreira; SARLET, Ingo Wolgang; STRECK, Lenio Luiz. Comentários à Constituição do Brasil. São Paulo : Saraiva, 2015. 
MARTINS, Carlos Eduardo Behrmann Rátis. Dever Geral de Recolhimento Domiciliar em Tempos de Coronavírus. In BAHIA, Saulo José Casali. Direitos e Deveres Fundamentais em tempos de Coronavírus. São Paulo : IASP, 2020.

ORGANIZAÇÃO MUNDIAL DA SAÚDE. WHO Coronavirus Disease (COVID-19) Dashboard Disponível em: https://covid19.who.int/. Acesso em 10 MAI 2020.

SARLET, Ingo Wolfgang. A Eficácia dos Direitos Fundamentais : Uma Teoria Geral dos Direitos Fundamentais na Perspectiva Constitucional. 11 ed. Porto Alegre : Livraria do Advogado, 2012.

SAMPAIO, José Adércio Leite. Teoria da Constituição e dos Direitos Fundamentais. Belo Horizonte : Del Rey, 2013.

SARMENTO, Leonardo. Controle de Constitucionalidade e Temáticas Afins. 2 ed. Rio de Janeiro : Lumen Juris, 2016.

TAVARES, André Ramos. Teoria da Justiça Constitucional. São Paulo : Saraiva, 2005.

THAMAY, Rennan Faria Krüger; TESHEINER, José Maria Rosa. Teoria Geral do Processo. 4 ed. São Paulo : Saraiva, 2019. 